\title{
High risk of invasive fungal disease in children undergoing hematopoietic cell transplantation or complex anticancer therapy: adverse role of post-transplant CMV replication
}

\author{
Jan Styczyński”* (D, Przemysław Gałązka”, Krzysztof Czyżewski, Natalia Bartoszewicz, \\ Joanna Cisek, Anna Dąbrowska, Ewa Demidowicz, Robert Dębski, Magdalena Dziedzic, \\ Marlena Ewertowska, Elżbieta Grześk, Agnieszka Jatczak-Gaca, Andrzej Kołtan, Sylwia Kołtan, \\ Piotr Księżniakiewicz, Monika Łęcka, Agata Marjańska, Monika Pogorzała, \\ Monika Richert-Przygońska, Barbara Tejza, Anna Urbańczyk, Hanna Żołnowska, Mariusz Wysocki \\ Department of Pediatric Hematology and Oncology, Collegium Medicum in Bydgoszcz, Nicolaus Copernicus University in Toruń, \\ Jurasz University Hospital 1, Bydgoszcz, Poland \\ "Authors contributed equally to study and share first co-authorship
}

\section{Abstract}

Introduction: We analyzed the epidemiology and outcomes of treatment of invasive fungal disease (IFD) in children during anticancer therapy (PHO, pediatric hematology and oncology) or after hematopoietic cell transplantation (HCT) over a period of eight consecutive years in a single-center study.

Material and methods: Overall, a total of 254 HCTs were performed, and 415 children were newly diagnosed for malignancy. Incidence, epidemiology and outcome of IFD were analyzed.

Results: The cumulative incidence of any IFD was $32.6 \%$ in allogeneic hematopoietic cell transplantation (allo-HCT), $22.2 \%$ in $\mathrm{PHO}$, and $6.0 \%$ in autologous hematopoietic cell transplantation patients (auto-HCT). The incidence of proven +probable IFD was $12.6 \%, 10.4 \%$, and $6.0 \%$, respectively. As many as $77.0 \% \mathrm{HCT}$ and $67.4 \%$ PHO of fungal episodes occurred in acute leukemia patients: the highest incidence of any IFD was observed for acute lymphoblastic leukemia (29.3\% in HCT; 40.5\% in PHO) and for acute myeloblastic leukemia (51.1\% in HCT; 65.0\% in PHO) patients. There were no significant differences in the incidence of fungal infections in both allo-HCT and PHO patients between the 2-year periods. Factors contributing to an increased risk of IFD in allo-HCT patients were: cytomegalovirus replication, and acute and chronic graft-versus-host disease. Survival from IFD was 91.9\% in PHO, and $78.1 \%$ in HCT patients. Fungal pneumonia in HCT patients resolved in $62.9 \%$, while in $\mathrm{PHO}$ patients it resolved in $93.5 \%$.

Conclusions: The risk of IFD in allo-HCT patients is much higher than in auto-HSCT and PHO patients. The outcome of IFD is better in PHO and auto-HCT than in allo-HCT settings.

Key words: fungal infections, malignant diseases, pediatric hematology and oncology, hematopoietic cell transplantation, children

Acta Haematologica Polonica 2021; 52, 5: 483-492

\footnotetext{
*Address for correspondence: Jan Styczynski, Department of Pediatric Hematology and Oncology, Collegium Medicum, Nicolaus Copernicus University Toruń, Skłodowskiej-Curie 9, 85-094 Bydgoszcz, Poland, phone +4852 5854860, fax +4852 5854087, e-mail: jstyczynski@cm.umk.pl

PTHiT Copyright (c) 2021 The Polish Society of Haematologists and Transfusiologists, Insitute of Haematology and Transfusion Medicine. All rights reserved.
} 


\section{Introduction}

Infections constitute a major problem in patients undergoing oncological treatment or hematopoietic cell transplantation (HCT) [1-4]. These complications can compromise the benefit of both anticancer therapy and transplantation. Oncological wards and transplant units are usually equipped with specific programs or guidelines for diagnostics, as well as for prophylactic, empirical, pre-emptive and targeted therapeutic management against bacteria, viruses, fungi and parasites [5-9]. To date, no strategy has proved entirely successful, and thus each center should be aware of its local infectious epidemiology.

In 2012, a nationwide program on infections in Polish pediatric hematology oncology (PHO) and transplant centers was initiated (acronym: iPhot) [10]. This program enabled assessment of the incidence and outcome of infections in $\mathrm{PHO}$ and pediatric $\mathrm{HCT}$ centers in various aspects [10-12], including differential analysis with the adult HCT population [13]. Results of multicenter analyzes based on the data from 2012-2017 have shown that the worst outcome was observed in cases of fungal infections, especially invasive fungal disease (IFD) in a transplant setting, both in children and adults $[10,13,14]$. These findings justify a focused approach to antifungal management based on the use of antifungal prophylaxis in subgroups of patients with the highest incidence of IFD, e.g. in patients undergoing allogeneic HCT (allo-HCT) or chemotherapy for acute leukemia.

In this context, we analyzed the epidemiology and outcome of treatment of IFD in a single-center pediatric study, updated for another two years.

Thus, the objective of this study was analysis of the incidence and outcome of fungal infections in children during anticancer therapy ( $\mathrm{PHO}$, pediatric hematology and oncology) or after HCT over a period of eight consecutive years in a single-center pediatric study.

\section{Material and methods}

\section{Patients}

All children newly diagnosed for malignancy or undergoing HCT during 96 consecutive months between 2012 and 2019 were included in the study: 415 patients with newly-diagnosed malignancies, and 254 patients after HCT [including 187 allo-HCT and 67 autologous hematopoietic cell transplantation patients (auto-HCT)].

\section{Study design}

Eight years of epidemiology and outcomes of IFD were analyzed. Data was collected on the basis of consecutive 2-year periods determined by the introduction of a national program of antifungal prophylaxis with the second generation of azoles: i.e. before prophylaxis (2012-2013), a transitional period (2014-2015), a period with modern prophylaxis (2016-2017), and a continuation period. In 2012-2013 the study was retrospective, and from 2014 it was prospective.

\section{Oncological treatment in acute leukemia}

During the analyzed eight-year period, all patients with acute lymphoblastic leukemia (ALL) were treated with the Intercontinental Cooperative ALL-IC-2009 protocol up to 30 September 2018, and subsequently with the AIEOP-BFM-2017 protocol. Patients with acute myeloid leukemia (AML) were treated according to the Berlin-Frankfurt-Munster AML-BFM-2004 protocol up to 2014, and subsequently with the AML-BFM-2012 protocol.

\section{Diagnosis of fungal infections}

Diagnoses of IFD were made, according to the EORTC/MSG criteria, as proven, probable, or possible $[15,16]$. All HCT and $\mathrm{PHO}$ patients were screened with a galactomannan test mainly during neutropenia, or on the basis of clinically-driven indications. Computed tomography (CT), including high-resolution CT (HRCT) or magnetic resonance imaging (MRI) of an area involved in infection, was performed also on the basis of clinical indications [17]. In cases of a new episode of fever, microbiological specimens were used for culture. Biopsy of involved tissue was made where this was possible and clinically justified [17, 18].

\section{Anti-fungal management and supportive therapy}

Standard uniform anti-infective prophylaxis, including an environmental prophylactic strategy, was applied to patients undergoing HCT [19-21]. Empirical, preemptive or targeted anti-fungal therapy was administered with various antifungal agents according to the current commonly accepted strategies [9, 17]. Antifungal prophylaxis was used routinely in allo-HCT patients during the neutropenic phase or immunosuppressive therapy, and usually included fluconazole or other azoles up to 2014. Subsequently, posaconazole or voriconazole was used in allo-HCT patients in cases of graft-versus-host disease (GvHD), and in patients with AML or high-risk ALL during conventional chemotherapy, as well as for secondary prophylaxis. In patients with ALL, prophylaxis with azoles was rarely used during the induction phase due to the potential risk of interaction with vincristine, leading to neurotoxicity and other adverse events. During the intensification/consolidation phase, antifungal prophylaxis was used between cycles of chemotherapy, while usually being temporarily withdrawn during chemotherapy with the use of non-azole antifungal in selected patients. Commercial intravenous immunoglobulins were administered monthly in cases of decreased serum immunoglobulin concentration after transplantation or oncological therapy until B-cell function recovery. 
Antibacterial antibiotic prophylaxis was used in all HCT patients during neutropenia or immunosuppressive therapy, and included penicillin or cephalosporin or ciprofloxacine. Preemptive or targeted anti-viral therapy was applied according to commonly accepted strategies.

\section{Infection-related mortality}

Treatment-related mortality (TRM) was defined as any death occurring at any point after the start of treatment that did not occur as a result of relapse or secondary malignancy. Outcome of infection was regarded as positive in cases of survival from infection or negative in cases of death occurring with an infectious complication. For the purpose of this study, infection-related mortality (IRM) analysis was restricted to fungal infections, being defined as any death occurring in the presence of IFD, starting from the day of diagnosis of the infection. In cases of relapse or progression of malignancy, this event was regarded as the primary cause of death, regardless of any diagnosis of concomitant infection.

\section{Ethics}

The authors confirm that the ethical policies of the journal, as noted on the journal's author guidelines page, have been adhered to, and that appropriate ethical review committee approval has been received.

\section{Statistical analysis}

Cumulative incidences of fungal infections were calculated using competing risk analysis, starting from the day of transplant in an HCT setting, or the day of cancer diagnosis in a PHO setting, to the day of the first infection. Death was considered as the competing event. For the purpose of cumulative incidence analysis, an event was defined as the diagnosis of a first specific infectious disorder. Non-categorical variables were compared with a Mann-Whitney $\mathrm{U}$ test, and categorical variables were compared with a chisquare test. Hazard risk (HR) and 95\% confidence intervals $(95 \% \mathrm{Cl})$ were calculated for the difference in occurrence of infections in patients. The Kaplan-Meier method was used to determine survival from invasive fungal infection.

Multivariate models for the development of fungal infections were calculated using the logistic regression model. Variables analyzed in HCT patients included: age ( $\leq 10$ years, $>10$ years); sex (female, male); donor source (matched sibling donor, MSD; mis/matched unrelated donor, MUD/ /MMUD); disease (acute leukemia, other); conditioning intensity (myeloablative, other); donor/recipient CMV serostatus (negative/negative, any positive); CMV replication (absent/present); acute GvHD occurring before infection onset (grade 0/1, grade 2-4); and chronic GvHD occurring before infection onset (no, yes). Use of anti-thymocyte globulin (ATG) was a variable dependent on alternative donor, as it was used almost exclusively in MUD/MMUD transplants.
The stepwise selection procedure was used to select significant covariates. All reported $p$-values are two-sided; $p$ $<0.05$ was considered as statistically significant.

\section{Results}

\section{Demographics}

Over the analyzed period of 96 consecutive months, a total of 415 PHO patients were newly diagnosed for malignancy, including 121 with ALL, 20 with acute myeloblastic leukemia (AML), 35 with non-Hodgkin lymphoma (NHL), 39 with Hodgkin's disease (HD), 61 with central nervous system tumors (CNS), 20 with neuroblastoma (NBL), 17 with Wilms tumor (WT), 13 with Ewing sarcoma (ES), six with osteosarcoma (OST), 25 with rhabdomyosarcoma (RMS), 13 with germ cell tumors (GCT), and 25 with other solid tumors (ST). During this period, a total of 254 HCTs were performed including 187 allo-HCTs and 67 auto-HCTs. Children were transplanted due to ALL ( $n=82), \operatorname{AML}(n=45)$, $\mathrm{NHL} / \mathrm{HD}(\mathrm{n}=19)$, MDS $(\mathrm{n}=10)$, bone marrow failure syndromes (BMF, $n=25$ ), primary immunodeficiency (PID, $n=15)$, neuroblastoma (NBL, $n=32)$, Ewing sarcoma $(n=13)$, or other diseases $(n=13)$ (Table I).

\section{Incidence of infections}

The cumulative incidence of fungal infections between 2012 and 2019 in $\mathrm{PHO}$ patients was 22.2\% (95\% Cl $=18.2-26.2)$, while in HCT patients it was $25.3 \%(95 \% \mathrm{Cl}$ $=20.0-30.6)(p=0.214)$ (Figure 1). The overall risk of any

Table I. Primary diseases of analyzed patients

\begin{tabular}{|c|c|c|}
\hline Variable & НСТ & PHO \\
\hline Total & $\begin{array}{c}254 \text { (187 allo, } \\
67 \text { auto) }\end{array}$ & 415 \\
\hline $\begin{array}{l}\text { Acute lymphoblastic } \\
\text { leukemia }\end{array}$ & 82 & 121 \\
\hline $\begin{array}{l}\text { Acute myeloblastic } \\
\text { leukemia }\end{array}$ & 45 & 20 \\
\hline $\begin{array}{l}\text { Non-Hodgkin } \\
\text { lymphoma }\end{array}$ & 9 & 35 \\
\hline Hodgkin's disease & 10 & 39 \\
\hline Solid tumors & $\begin{array}{c}58 \text { (32 NBL, } \\
13 \mathrm{ES}, \\
13 \text { other) }\end{array}$ & $\begin{array}{c}180 \text { (61 CNS, } \\
20 \text { NBL, } 17 \text { WT, } \\
13 \text { ES, } 6 \text { OST, } \\
25 \text { RMS, } \\
13 \text { GCT, } \\
25 \text { other) }\end{array}$ \\
\hline Other & $\begin{array}{c}15 \text { PID, } 25 \text { BMF, } \\
10 \text { MDS }\end{array}$ & $\begin{array}{c}13 \mathrm{LCH}, 2 \mathrm{CML}, \\
2 \mathrm{MDS}\end{array}$ \\
\hline
\end{tabular}

HCT - hematopoietic cell transplantation; PHO - pediatric hematology and oncology; allo - allogeneic; auto - autologous; NBL - neuroblastoma; ES - Ewing sarcoma; CNS - central nervous system tumor; WT - Wilms tumor; OST - osteosarcoma; RMS - rhabdomyosarcoma; GCT - germ cell tumor; PID - primary immunodeficiency; BMF - bone marrow failure syndrome; MDS - myelodysplastic syndrome; LCH - Langerhans cell histiocytosis; CML - chronic myeloid leukemia 

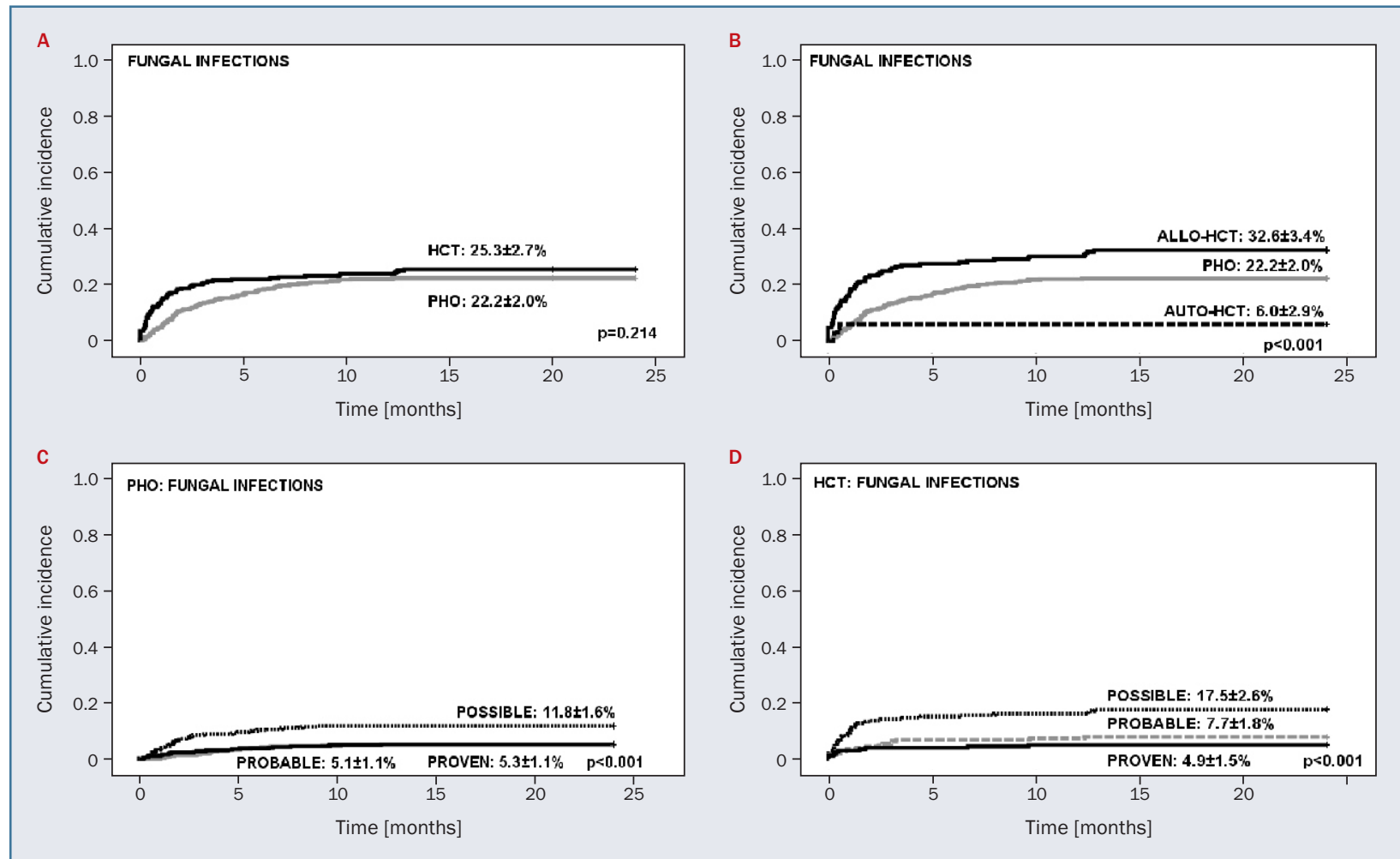

Figure 1. Cumulative incidence of invasive fungal disease (IFD): A. In pediatric hematology and oncology (PHO) versus hematopoietic cell transplantation (HCT); B. In PHO versus allogeneic hematopoietic cell transplantation (allo-HCT) versus autologous hematopoietic cell transplantation patients (auto-HCT); C. In PHO with respect to level of IFD diagnosis; D. In HCT with respect to level of IFD diagnosis

IFD in HCT (allo +auto) vs. PHO patients was similar: HR $=1.2(95 \% \mathrm{Cl}=0.8-1.7 ; p=0.357)$. Also, the risk of proven + probable IFD for HCT (allo +auto) vs. PHO was similar: HR $=1.1(95 \% \mathrm{Cl}=0.6-1.8 ; p=0.897)$. With respect to the type of transplant, the cumulative incidence of fungal infections was much higher after allo-HCT than after auto-HCT: $32.6 \%$ vs. $6.0 \%(\mathrm{HR}=7.6,95 \% \mathrm{Cl}=2.6-22.0 ; p<0.0001)$.

There were no significant differences in the incidence of fungal infections both in allo-HCT and PHO patients between the 2-year periods. Respective values for subsequent two-year periods for PHO vs. HCT were: $14.8 \%$ vs. $24.2 \%$ for $2012-2013$ ( $p=0.092$ ), $24.2 \%$ vs. $22.0 \%$ for $2014-$ $-2015,(p=0.8), 25.0 \%$ vs. $28.8 \%$ for $2016-2017(p=0.4)$, and $25.7 \%$ vs. $26.0 \%$ for $2018-2019(p=0.8)$.

The majority of fungal infections occurred within the first four months, and earlier after allo-HCT than in PHO patients after diagnosis of the malignancy. The median time to first fungal infection was shorter after allo-HCT than in PHO patients after diagnosis of malignancy: 2.2 months vs. 3.5 months, $p<0.001$. Due to sporadic infections after auto-HCT, a respective comparison was not carried out.

The overall risk of any IFD in allo-HCT vs. PHO patients was significantly higher up to day 100 (from transplant or cancer diagnosis, respectively): HR $=2.3$ (95\%
$\mathrm{Cl}=1.5-3.5 ; p<0.001)$, and then lower after day 100: $\mathrm{HR}=0.5(95 \% \mathrm{Cl}=0.3-1.0 ; p=0.073)$. The overall risk of proven + probable IFD in allo-HCT vs. PHO patients was significantly higher up to day 100 (from transplant or cancer diagnosis, respectively): $\mathrm{HR}=2.5(95 \% \mathrm{Cl}=1.3-4.7$; $p=0.006)$, and then lower after day 100: HR $=0.4(95 \%$ $\mathrm{Cl}=0.1-1.1 ; p=0.098)$.

The cumulative incidence of IFD among PHO patients was $22.2 \%$, including proven IFD in $5.3 \%$, probable in $5.1 \%$, and possible in $11.8 \%$ of patients (Figure 2). As many as $67.4 \%$ of IFD episodes occurred in acute leukemia patients. IFD incidence was $40.5 \%$ among ALL patients (proven $8.3 \%$, probable $10.7 \%$, possible $22.3 \%$ ), and $65.0 \%$ among AML patients (proven $15.0 \%$, probable $5.0 \%$, possible $45.0 \%$ ). In other types of cancer, the incidence of IFD was: NHL 25.7\%, RMS 12.0\%, CNS 9.8\%, NBL 20.0\%, ES 7.7\%, GCT 7.7\%, WT 0\%, osteosarcoma 0\%, and other solid tumors $20.0 \%$.

IFD incidence among allo-HCT patients was $32.6 \%$, including proven in $4.9 \%$, probable in $7.7 \%$, and possible IFD in $17.5 \%$ patients (Figure 1). Altogether, $77 \%$ of the IFD cases were reported in acute leukemia patients. IFD incidence was $29.3 \%$ among ALL (proven 4.9\%, probable $7.3 \%$, possible $17.1 \%$ ), and $51.1 \%$ among AML patients (proven $2.2 \%$, probable $13.3 \%$, possible $35.6 \%$ ). The incidence of 


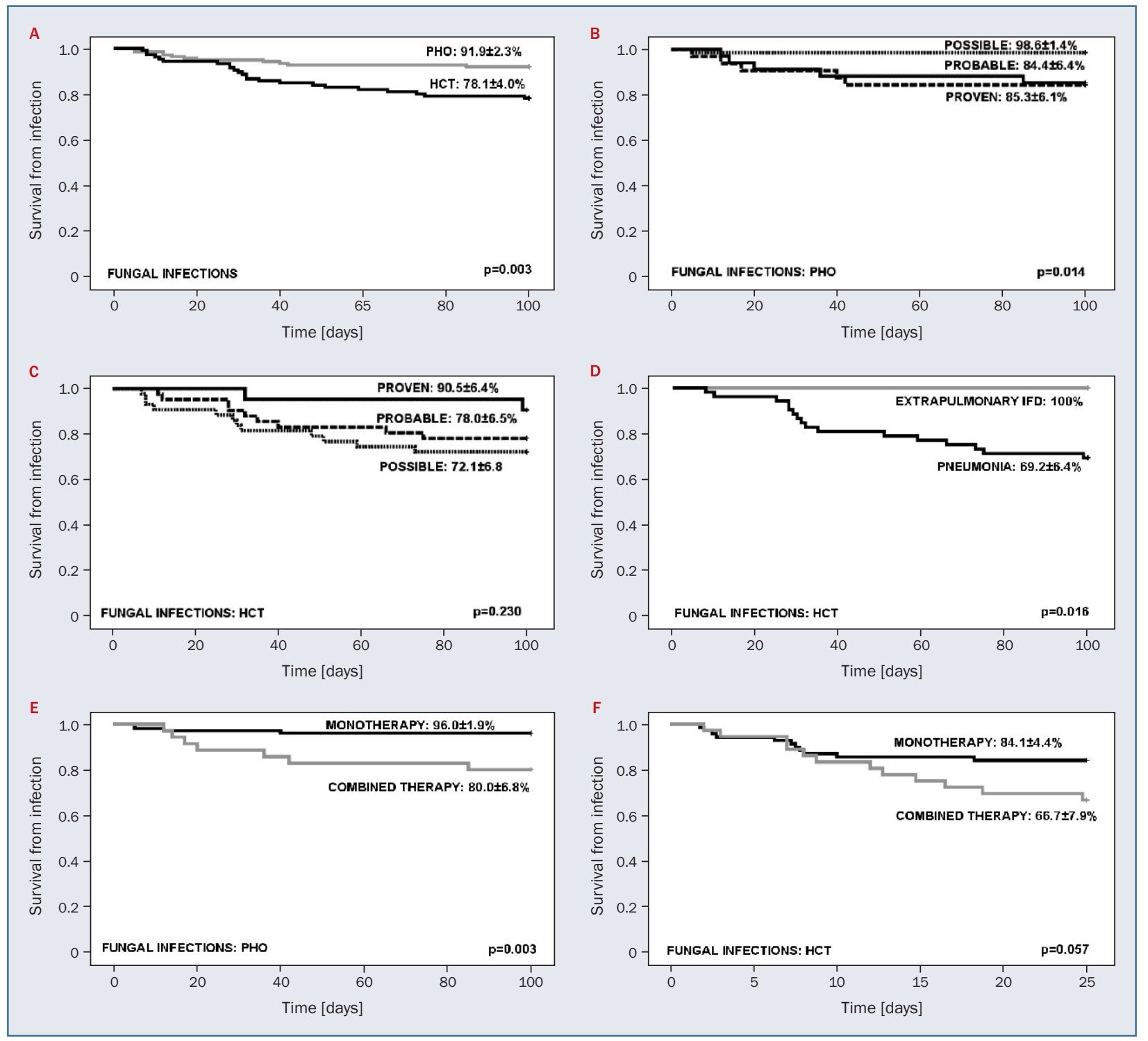

Figure 2. Survival from invasive fungal disease (IFD): A. In pediatric hematology and oncology (PHO) versus hematopoietic cell transplantation (HCT); B. In PHO with respect to level of diagnosis; C. In HCT with respect to level of IFD diagnosis; D. In HCT patients in pulmonary versus extrapulmonary IFD; E. In PHO with respect to antifungal monotherapy versus combined therapy; $\mathrm{F}$. In HCT patients with respect to antifungal monotherapy versus combined therapy

IFD was $36.0 \%$ in BMF, $30.0 \%$ in MDS, and $13.3 \%$ in PID. Additionally, the incidence of IFD in auto-HCT was $6.3 \%$ in $\mathrm{NBL}, 11.1 \%$ in NHL, and $10 \%$ in HD.

The number of infections with respect to time periods is shown in Table II. Proven IFDs were diagnosed in $22 \mathrm{PHO}$ and $13 \mathrm{HCT}$ patients, with 25 and 13 identified fungal species, respectively (Table III). Candida spp. was the most prevalent causative factor, detected mainly as a blood-stream infection.

\section{Risk factors of infections in allo-HCT patients} Factors contributing to an increased risk of fungal infections both in uni- and multivariate analysis were: $\mathrm{CMV}$ replication, and acute and chronic GvHD (Table IV). Fungal infections were also less likely after non-myeloablative or reduced-intensity conditioning, although this did not reach statistical significance.

\section{Survival after fungal infections}

Survival from IFD was $91.9 \%$ in PHO, and $78.1 \%$ in HCT patients. With respect to IFD level of diagnosis in PHO, patients with possible IFD had a $98.6 \%$ cure rate, while probable and proven IFD had comparable cure rates of 84-85\% (Figure 2). In HCT patients, no significant differences were found in the cure rate, although possible IFD resolved in $72.1 \%$, probable in $78.0 \%$, and proven 
Table II. Hazard risk of infections after hematopoietic cell transplantation (HCT) compared to pediatric hematology and oncology (PHO) patients with respect to time periods

\begin{tabular}{|c|c|c|c|c|c|c|}
\hline Infections & Total & $0-30$ days & $31-100$ days & $101-180$ days & $181-365$ days & $>365$ days \\
\hline \multicolumn{7}{|l|}{$\begin{array}{l}\text { allo-HCT } \\
(n=187)\end{array}$} \\
\hline Total & 61 & 33 & 17 & 2 & 5 & 4 \\
\hline Proven & $9(14.8 \%)$ & $5(15.2 \%)$ & $2(11.8 \%)$ & $0(0 \%)$ & $2(40.0 \%)$ & $0(5.0 \%)$ \\
\hline Probable & $16(26.2 \%)$ & 7 (21.2\%) & $7(41.2 \%)$ & $0(0 \%)$ & $1(20.0 \%)$ & $1(25.0 \%)$ \\
\hline $\begin{array}{l}\text { Possible } \\
\text { auto-HCT } \\
(\mathrm{n}=67)\end{array}$ & 36 (59.0\%) & $21(63.6 \%)$ & $8(47.0 \%)$ & $2(100 \%)$ & 2 (40.0\%) & $3(75.0 \%)$ \\
\hline Total & 4 & 4 & & & & \\
\hline Proven & 4 (100\%) & $4(100 \%)$ & & & & \\
\hline Probable & $0(0 \%)$ & $0(0 \%)$ & & & & \\
\hline Possible & $0(0 \%)$ & $0(0 \%)$ & & & & \\
\hline \multicolumn{7}{|l|}{$\mathrm{PHO}(\mathrm{n}=415)$} \\
\hline Total & 92 & 20 & 37 & 19 & 15 & 1 \\
\hline Proven & 22 (23.9\%) & 5 (25.0\%) & 7 (18.9\%) & 4 (21.0\%) & $5(33.3 \%)$ & $1(100 \%)$ \\
\hline Probable & $21(22.8 \%)$ & $1(5.0 \%)$ & 7 (18.9\%) & 9 (47.4\%) & $4(26.7 \%)$ & $0(0 \%)$ \\
\hline Possible & 49 (53.3\%) & 14 (70.0\%) & $23(62.2 \%)$ & $6(31.6 \%)$ & $6(40.0 \%)$ & $0(0 \%)$ \\
\hline Hazard risk & $H R=1.7$ & $\mathrm{HR}=4.2$ & $H R=1.0$ & $H R=0.2$ & $\mathrm{HR}=0.7$ & $H R=9.0$ \\
\hline $\begin{array}{l}\text { (allo-HCT } \\
\text { vs. PHO) }\end{array}$ & $95 \% \mathrm{Cl}=1.2-2.5$ & $95 \% \mathrm{Cl}=2.6-7.6$ & $95 \% \mathrm{Cl}=0.6-1.8$ & $\begin{array}{c}95 \% \mathrm{Cl}=0.05- \\
-0.97\end{array}$ & $95 \% \mathrm{C}=0.3-2.0$ & $95 \% \mathrm{Cl}=1.0-81$ \\
\hline Total IFD & $p=0.008$ & $p<0.001$ & $p=0.999$ & $p=0.053$ & $p=0.726$ & $p=0.058$ \\
\hline Hazard risk & $H R=1.3$ & $\mathrm{HR}=4.7$ & $H R=1.4$ & $H R=N D$ & $\mathrm{HR}=0.7$ & $H R=2.2$ \\
\hline $\begin{array}{l}\text { (allo-HCT } \\
\text { vs. PHO) }\end{array}$ & $95 \% \mathrm{Cl}=0.8-2.3$ & $95 \% \mathrm{Cl}=1.7-12$ & $95 \% \mathrm{Cl}=0.6-3.4$ & $95 \% \mathrm{Cl}=\mathrm{ND}$ & $95 \% \mathrm{Cl}=0.2-2.7$ & $95 \% \mathrm{Cl}=0.1-35$ \\
\hline $\begin{array}{l}\text { Proven/ } \\
\text { /probable }\end{array}$ & $p=0.341$ & $p=0.002$ & $p=0.533$ & $p=0.032$ & $p=0.885$ & $p=0.999$ \\
\hline
\end{tabular}

allo - allogeneic; auto - autologous; HR - hazard risk; $\mathrm{Cl}$ - confidence interval; $\mathrm{p}$ - $\mathrm{p}$-value; ND - not determined

in $90.5 \%$. Fungal pneumonia in HCT patients resolved only in $62.9 \%$ vs. $100 \%$ in extrapulmonary involvement ( $p=0.016)$, while in $\mathrm{PHO}$ patients there were no differences: $93.5 \%$ vs. $88.4 \%$ ( $p=0.3$ ). Antifungal monotherapy was related to a higher cure rate than combined antifungal treatment, both in $\mathrm{PHO}$ patients $(96.0 \%$ vs. $80.0 \%$, $p=0.003$ ), and HCT patients ( $84.1 \%$ vs. $66.7 \%, p=0.057$ ). However, it should be noted that combined antifungal therapy was used in cases of a lack of improvement of initial therapy.

\section{Discussion}

This long-term study of the incidence and outcome of fungal infections in children during anticancer therapy (PHO) or after undergoing HCT in a single-center analysis has shown comparably high incidences of both any and proven + probable IFD in allo-HCT and PHO patients, and much lower incidence in auto-HCT.

In other studies, infections occur in overall $82 \%$ of children after allo-HCT [23], 21\% after auto-HCT, and $49 \%$ with acute leukemia in a PHO setting [24]. With respect to HCT recipients, infections accounted for $13 \%$ of deaths after matched sibling donor HCT, 17\% after unrelated donor HCT, and 7\% after auto-HCT [25]. IFD was diagnosed in $12 \%$ of children within the first 30 days after allo-HCT [23], and was rare after auto-HCT [24]. In general, $53 \%$ all allo-HCT infectious deaths were caused by fungi, $20 \%$ by bacteria, $24 \%$ by viruses, and $3 \%$ by parasites [23], while deaths due to infections were rare after auto-HCT [24]. In analysis of autopsies, infections have been found to be the cause of death in $55 \%$ of adults 
Table III. Etiology of proven fungal infections

\begin{tabular}{l|c|c} 
Infection & PHO & HCT \\
(25 species & (13 species \\
in 22 patients) & in 13 patients) \\
\hline
\end{tabular}

\section{Candida:}

- albicans

- glabrata

- krusei

- parapsilosis

- dubliniensis

- Iusitaniae

- guilliermonde

Aspergillus:

- fumigatus

- flavus

Other:

- Rhizopus mucoralis

- Lichteimia corymbifera

- Fusarium

*Denotes fluconazole-sensitive strains of non-albicans Candida; PHO - pediatric hematology and oncology; HCT - hematopoietic cell transplantation after allo-HCT, and in 18\% after auto-HCT [26]. Overall, IFD, cytomegalovirus (CMV) and bacteria are the main non-relapse risk factors for deaths after HCT [27, 28].

In this context, our analysis has shown a higher incidence of any IFD both in PHO and allo-HCT settings. However, when proven or probable IFDs are taken into account, the incidences are comparable to other international pediatric data. It remains unclear which is the real threat of IFD diagnosed on a 'possible' level, something which is being diagnosed in over $50 \%$ of IFD cases, both in PHO and allo-HCT settings. Surprisingly, the outcome of possible IFD, although non-significantly, was lower than probable or proven IFD in HCT patients. This was not the case in PHO patients. The proven worse outcomes of possible IFDs lead to the issue of diagnosis at the level of biomarkers, imaging and tissue biopsy.

Given that in the majority of cases the possible IFD was diagnosed in patients with pneumonia, based on clinical signs and symptoms, and computed tomography imaging, it must be underscored that invasive diagnostics in a pediatric population in such cases is very difficult. Neither bronchoscopy with broncho-alveolar lavage (BAL), nor lung biopsy, is a standard procedure yet in children after

Table IV. Risk factor analysis for fungal infections in allogeneic hematopoietic cell transplantation patients

\begin{tabular}{|c|c|c|c|c|c|}
\hline \multirow[t]{2}{*}{ Variable } & \multirow[t]{2}{*}{ Characteristics } & \multicolumn{2}{|c|}{ Univariate analysis } & \multicolumn{2}{|c|}{ Multivariate analysis } \\
\hline & & Frequency & $p$-value & RR $(95 \% \mathrm{Cl})$ & $p$-value \\
\hline \multirow[t]{2}{*}{ Sex } & Female & 25/76 (32.9\%) & 0.999 & 1 & 0.999 \\
\hline & Male & $36 / 113(31.9 \%)$ & & $1.0(0.5-1.9)$ & \\
\hline \multirow[t]{2}{*}{ Age } & $<10$ years & 31/98 (31.6\%) & 0.967 & 1 & 0.972 \\
\hline & $>10$ years & 30/91 (33.0\%) & & $1.1(0.5-1.7)$ & \\
\hline \multirow[t]{2}{*}{ Disease } & Other & $17 / 50(34.0 \%)$ & 0.946 & 1 & 0.985 \\
\hline & Acute leukemia & 44/137 (32.1\%) & & $0.9(0.5-2.1)$ & \\
\hline \multirow[t]{2}{*}{ Donor } & MFD & 12/35 (33.3\%) & 0.934 & 1 & 0.921 \\
\hline & other & 49/154 (31.8\%) & & $0.9(0.5-2.4)$ & \\
\hline \multirow[t]{2}{*}{ Conditioning } & Myeloablative & $52 / 145$ (35.9\%) & 0.083 & 1 & 0.075 \\
\hline & $\mathrm{RIC}$ & $9 / 44(20.5 \%)$ & & $0.5(0.2-1.1)$ & \\
\hline \multirow[t]{2}{*}{ CMV serostatus (recipient) } & Negative & $5 / 28(17.9 \%)$ & 0.121 & 1 & 0.098 \\
\hline & Positive & $56 / 161(34.8 \%)$ & & $2.4(0.9-6.8)$ & \\
\hline \multirow[t]{2}{*}{ CMV replication } & Negative & 5/93 (5.4\%) & $<0.001$ & 1 & $<0.001$ \\
\hline & Positive & $56 / 96(58.3 \%)$ & & $24(9-66)$ & \\
\hline \multirow[t]{2}{*}{ Acute GvHD $\geq 2$} & No & $45 / 165(27.3 \%)$ & $<0.001$ & 1 & $<0.001$ \\
\hline & Yes & $16 / 24(66.7 \%)$ & & $5.3(2.1-13)$ & \\
\hline \multirow[t]{2}{*}{ Chronic GvHD } & No & $1 / 158(0.6 \%)$ & 0.682 & 1 & 0.725 \\
\hline & Yes & $10 / 11(90.9 \%)$ & & $157(91->1,000)$ & \\
\hline \multirow[t]{2}{*}{ Any GvHD } & No & $35 / 154$ (22.7\%) & $<0.001$ & 1 & $<0.001$ \\
\hline & Yes & $26 / 35$ (74.3\%) & & $9.8(4.2-23)$ & \\
\hline
\end{tabular}

$p$ - p-value; RR - relative risk; $\mathrm{Cl}$ - confidence interval; MFD - matched family donor; RIC - reduced-intensity conditioning; CMV - cyclomegalovirus; GvHD - graft-versus-host-disease 
allo-HCT, although both these diagnostic techniques are being performed more frequently nowadays.

Another surprising outcome of our study is the better survival after antifungal monotherapy than after combined therapy. In general, it has been proven that combination therapy is more successful than monotherapy in first-line therapy of IFD [29]. In our study, however, combination therapy was applied almost exclusively as the second-line treatment after a lack of improvement in first-line therapy. This aligns with national [17] and international recommendations [9].

Our study highlights the negative role of CMV replication as an adverse factor leading to increased incidence of IFD. This indirect effect of viral infection is also a risk factor of mortality after $\mathrm{HCT}[30,31]$.

Antifungal prophylaxis introduced in HCT patients and in patients with acute leukemias in 2014-2015, slowed down the increase in incidence of fungal infections from 2016 onwards, although it did not stop it. Looking into possible activities, other options to improve the outcome of IFD might be: wider use of invasive diagnostics, treatment with reference antifungals according to recommendations [9, 17], use of minimally-invasive surgery in diagnostics and treatment [32,33], or successful prophylaxis and treatment of viral infections preceding development of IFD [4, 34, 35]. New diagnostic methods and antifungals may appear.

The strengths of our study are the collection of all necessary clinical data, as well as uniform diagnosis and treatment of patients. The same factors also serve as limitations of our study, because a single-center study carries the bias of a specific approach and similar interventions performed in the majority of patients.

In conclusion, the risk of IFD in allo-HCT patients is much higher than in auto-HSCT and PHO patients. Most fungal episodes occurred in acute leukemia patients, in both the allo-HCT and PHO groups. As expected, the outcome of IFD was better in the PHO and auto-HCT setting than in the allo-HCT setting. Fungal infection-related mortality was highest in transplant patients with pneumonia.

\section{Acknowledgements}

The authors thank all nurses from the Department of Pediatric Hematology and Oncology, Collegium Medicum in Bydgoszcz, Nicolaus Copernicus University in Toruń, Jurasz University Hospital 1, Bydgoszcz, Poland for their outstanding everyday care of our patients.

\section{Authors' contributions}

JS had primary responsibility for study design. JS and PG performed the analysis and wrote the manuscript. KC, $\mathrm{MD}, \mathrm{PG}$ and JS collected data. All authors contributed to data analysis and interpretation, and critical revision of the manuscript.

\section{Conflict of interest}

All authors declare no conflict of interest related to this study.

\section{Financial support}

None.

\section{Ethics}

The work described in this article has been carried out in accordance with The Code of Ethics of the World Medical Association (Declaration of Helsinki) for experiments involving humans; EU Directive 2010/63/EU for animal experiments; Uniform Requirements for manuscripts submitted to Biomedical journals.

\section{References}

1. Kontoyiannis DP, Marr KA, Park BJ, et al. Prospective surveillance for invasive fungal infections in hematopoietic stem cell transplant recipients, 2001-2006: overview of the Transplant-Associated Infection Surveillance Network (TRANSNET) Database. Clin Infect Dis. 2010; 50(8): 1091-1100, doi: 10.1086/651263, indexed in Pubmed: 20218877.

2. Styczyński J. Infectious complications in children and adults with hematological malignancies. Acta Haematologica Polonica. 2019; 50(3): 167-173, doi: 10.2478/ahp-2019-0027.

3. Maertens J, Marchetti O, Herbrecht R, et al. Third European Conference on Infections in Leukemia. European guidelines for antifungal management in leukemia and hematopoietic stem cell transplant recipients: summary of the ECIL 3-2009 update. Bone Marrow Transplant. 2011; 46(5): 709-718, doi: 10.1038/bmt.2010.175, indexed in Pubmed: 20661235.

4. Styczyński J. ABC of viral infections in hematology: focus on herpesviruses. Acta Haematologica Polonica. 2019; 50(3): 159-166, doi: 10.2478/ahp-2019-0026.

5. Averbuch D, Cordonnier C, Livermore DM, et al. ECIL4, a joint venture of EBMT, EORTC, ICHS, ESGICH/ESCMID and ELN. Targeted therapy against multi-resistant bacteria in leukemic and hematopoietic stem cell transplant recipients: guidelines of the 4th European Conference on Infections in Leukemia (ECIL-4, 2011). Haematologica. 2013; 98(12): 1836-1847, doi: 10.3324/haematol.2013.091330, indexed in Pubmed: 24323984.

6. Averbuch D, Orasch C, Cordonnier C, et al. ECIL4, a joint venture of EBMT, EORTC, ICHS, ESGICH/ESCMID and ELN. European guidelines for empirical antibacterial therapy for febrile neutropenic patients in the era of growing resistance: summary of the $20114^{\text {th }}$ European Conference on Infections in Leukemia. Haematologica. 2013; 98(12): 1826-1835, doi: 10.3324/haematol.2013.091025, indexed in Pubmed: 24323983.

7. Ljungman $\mathrm{P}$, de la Camara $\mathrm{R}$, Cordonnier $\mathrm{C}$, et al. European Conference on Infections in Leukemia. Management of CMV, HHV-6, HHV-7 and Kaposi-sarcoma herpesvirus (HHV-8) infections in patients with hematological malignancies and after SCT. Bone Marrow Transplant. 2008; 42(4): 227-240, doi: 10.1038/bmt.2008.162, indexed in Pubmed: 18587440 .

8. Styczynski J, Reusser P, Einsele H, et al. Second European Conference on Infections in Leukemia. Management of HSV, VZV and EBV infections in patients with hematological malignancies and after SCT: guidelines from the Second European Conference on 
Infections in Leukemia. Bone Marrow Transplant. 2009; 43(10): 757-770, doi: 10.1038/bmt.2008.386, indexed in Pubmed: 19043458.

9. Groll AH, Castagnola E, Cesaro S, et al. Fourth European Conference on Infections in Leukaemia, Infectious Diseases Working Party of the European Group for Blood Marrow Transplantation (EBMT-IDWP), Infectious Diseases Group of the European Organisation for Research and Treatment of Cancer (EORTC-IDG), International Immunocompromised Host Society (ICHS), European Leukaemia Net (ELN). Fourth European Conference on Infections in Leukaemia (ECIL-4): guidelines for diagnosis, prevention, and treatment of invasive fungal diseases in paediatric patients with cancer or allogeneic haemopoietic stem-cell transplantation. Lancet Oncol. 2014; 15(8): e327-e340, doi: 10.1016/S1470-2045(14)70017-8, indexed in Pubmed: 24988936.

10. Styczynski J, Czyzewski K, Wysocki M, et al. Polish Society of Paediatric Oncology and Haematology. Increased risk of infections and infection-related mortality in children undergoing haematopoietic stem cell transplantation compared to conventional anticancer therapy: a multicentre nationwide study. Clin Microbiol Infect. 2016; 22(2): 179. e1-179.e10, doi: 10.1016/j.cmi.2015.10.017, indexed in Pubmed: 26493843.

11. Salamonowicz M, Ociepa T, Frączkiewicz J, et al. Incidence, course, and outcome of Clostridium difficile infection in children with hematological malignancies or undergoing hematopoietic stem cell transplantation. Eur J Clin Microbiol Infect Dis. 2018; 37(9): 1805-1812, doi: 10.1007/s10096-018-3316-5, indexed in Pubmed: 29978303.

12. Czyzewski K, Galazka P, Zalas-Wiecek P, et al. Infectious complications in children with malignant bone tumors: a multicenter nationwide study. Infect Drug Resist. 2019; 12: 1471-1480, doi: 10.2147/IDR. S199657, indexed in Pubmed: 31213862.

13. Czyżewski K, Styczyński J, Giebel S, et al. for Polish Society of Pediatric Oncology and Hematology and Polish Society of Hematology and Blood Transfusion. Age-dependent determinants of infectious complications profile in children and adults after hematopoietic cell transplantation: lesson from the nationwide study. Ann Hematol. 2019; 98(9): 2197-2211, doi: 10.1007/s00277-019-03755-2, indexed in Pubmed: 31321454.

14. Czyżewski K, Gałązka P, Frączkiewicz J, et al. Epidemiology and outcome of invasive fungal disease in children after hematopoietic cell transplantation or treated for malignancy: Impact of national programme of antifungal prophylaxis. Mycoses. 2019; 62(11): 990-998, doi: 10.1111/myc.12990.

15. Donnelly JP, Chen SC, Kauffman CA, et al. Revision and update of the consensus definitions of invasive fungal disease from the european organization for research and treatment of cancer and the mycoses study group education and research consortium. Clin Infect Dis. 2020; 71(6): 1367-76, doi: 10.1093/cid/ciz1008, indexed in Pubmed: 31802125.

16. De Pauw P, Walsh TJ, Donnelly JP, et al. Revised definitions of invasive fungal disease from the european organization for research and treatment of cancer/invasive fungal infections cooperative group and the national institute of allergy and infectious diseases mycoses study group (EORTC/MSG) consensus group. Clin Infect Dis. 2008; 46(12): 1813-1821.

17. Gil L, Kałwak K, Piekarska A, et al. Antifungal management in adults and children with hematological malignancies or undergoing hematopoietic cell transplantation: recommendations of Polish Society of Hematology and Blood Transfusion, Polish Society of Pe- diatric Oncology and Hematology, and Polish Adult Leukemia Study Group, 2020. Acta Haematologica Polonica. 2020; 51(2): 60-72, doi: 10.2478/ahp-2020-0014.

18. Styczyński J, Czyżewski K, Frączkiewicz J, et al. Clinical spectrum and outcome of invasive mucormycosis in children and adults: Polish experience of the decade 2010-2019. Acta Haematologica Polonica. 2020; 51(3): 157-163, doi: 10.2478/ahp-2020-0028.

19. Styczynski J, Gil L. EBMT Paediatric Diseases Working Party. Prevention of infectious complications in pediatric HSCT. Bone Marrow Transplant. 2008; 42(Suppl 2): S77-S81, doi: 10.1038/bmt.2008.289, indexed in Pubmed: 18978751.

20. Styczyński J, Czyżewski K, Ussowicz M, et al. Antimicrobial prophylaxis in patients after hematopoietic cell transplantation: results of a survey of the Polish Federation of Bone Marrow Transplant Centers. Acta Haematologica Polonica. 2020; 51(3): 183-186, doi: 10.2478/ ahp-2020-0032.

21. Styczynski J, Tridello G, Donnelly JP, et al. Protective environment for hematopoietic cell transplant (HSCT) recipients: The Infectious Diseases Working Party EBMT analysis of global recommendations on health-care facilities. Bone Marrow Transplant. 2018; 53(9): 1131-1138, doi: 10.1038/s41409-018-0141-5, indexed in Pubmed: 29535381.

22. Gałązka P, Dziedzic M, Czyżewski K, et al. Differential risk of viral infections in children undergoing complex anticancer therapy or hematopoietic stem cell transplantation. Med Res J. 2018; 3(3): 127-133, doi: 10.5603/mrj.a2018.0021.

23. Srinivasan A, Wang C, Srivastava DK, et al. Timeline, epidemiology, and risk factors for bacterial, fungal, and viral infections in children and adolescents after allogeneic hematopoietic stem cell transplantation. Biol Blood Marrow Transplant. 2013; 19(1): 94-101, doi: 10.1016/j.bbmt.2012.08.012, indexed in Pubmed: 22922523.

24. Srinivasan A, McLaughlin L, Wang C, et al. Early infections after autologous hematopoietic stem cell transplantation in children and adolescents: the St. Jude experience. Transpl Infect Dis. 2014; 16(1): 90-97, doi: 10.1111/tid.12165, indexed in Pubmed: 24256514.

25. Pasquini MC, Zhu X. Current use and outcome of hematopoietic stem cell transplantation: CIBMTR Summary Slides. https://www.cibmtr. org/Pages/index.aspx (January 01, 2021).

26. Sinko J, Csomor J, Barta A, et al. Infection-related deaths in the haematopoietic stem cell transplant setting. Bone Marrow Transplant. 2012; 47(Suppl. 1): abstract 472.

27. Bjorklund A, Aschan J, Labopin M, et al. Risk factors for fatal infectious complications developing late after allogeneic stem cell transplantation. Bone Marrow Transplant. 2007; 40(11): 1055-1062, doi: 10.1038/sj.bmt.1705856, indexed in Pubmed: 17891187.

28. Martino R, Kerguelen A, Valcárcel D, et al. Reduction of infection-related mortality after allogeneic PBSCT from HLA-identical siblings: Iongitudinal analysis from 1994 to 2008 at a single institution. Bone Marrow Transplant. 2011; 46(5): 690-701, doi: 10.1038/bmt.2010.177, indexed in Pubmed: 20818448.

29. Marr KA, Schlamm HT, Herbrecht R, et al. Combination antifungal therapy for invasive aspergillosis: a randomized trial. Ann Intern Med. 2015; 162(2): 81-89, doi: 10.7326/M13-2508, indexed in Pubmed: 25599346.

30. Green ML, Leisenring W, Xie Hu, et al. Cytomegalovirus viral load and mortality after haemopoietic stem cell transplantation in the era of pre-emptive therapy: a retrospective cohort study. Lancet Haematol. 2016; 3(3): e119-e127, doi: 10.1016/S2352-3026(15)00289-6, indexed in Pubmed: 26947200. 
31. Styczyński J. Prophylaxis vs preemptive therapy in prevention of CMV infection: new insight on prophylactic strategy after allogeneic hematopoietic cell transplantation. Acta Haematologica Polonica. 2020; 51(1): 17-23, doi: 10.2478/ahp-2020-0005.

32. Galazka P, Czyzewski K, Marjanska A, et al. Minimally invasive surgery in pediatric oncology: proposal of guidelines. Anticancer Res. 2019; 39(11): 5853-5859, doi: 10.21873/anticanres.13789, indexed in Pubmed: 31704809.

33. Gałazka P, Redloch K, Kroczek K, et al. Minimally invasive surgery for congenital abdominal cystic lesions in newborns and infants. In Vivo. 2020; 34(3): 1215-1221, doi: 10.21873/invivo.11895, indexed in Pubmed: 32354912.
34. Styczynski J, Tridello G, Gil L, et al. Prognostic impact of Epstein-Barr virus serostatus in patients with nonmalignant hematological disorders undergoing allogeneic hematopoietic cell transplantation: the study of Infectious Diseases Working Party of the European Society for Blood and Marrow Transplantation. Acta Haematologica Polonica. 2020; 51(2): 73-80, doi: 10.2478/ ahp-2020-0015.

35. Garcia-Vidal C, Upton A, Kirby KA, et al. Epidemiology of invasive mold infections in allogeneic stem cell transplant recipients: biological risk factors for infection according to time after transplantation. Clin Infect Dis. 2008; 47(8): 1041-1050, doi: 10.1086/591969, indexed in Pubmed: 18781877. 